www.jmscr.igmpublication.org

Impact Factor 5.84

Index Copernicus Value: 83.27

ISSN (e)-2347-176x ISSN (p) 2455-0450

crossref DOI: https://dx.doi.org/10.18535/jmscr/v5i1.131

Journal Of Medical Science And Clinical Research

IGM Publication

An Official Publication of IGM Publication

\title{
Modification of Solubility Test for the Diagnosis of Sickle Cell Disease
}

\author{
Authors \\ Dr Satyabrata Patra, MD (Pathology) Dr. Camellia Chanda, MBBS, PGDMCH
}

\begin{abstract}
Mass screening for sickle cell disease is very much needed. A screening test should be cheap, easy to perform, less cumbersome and should have high sensitivity, low specificity is accepted. TOT (turn over time, meaning time taken for a single cycle of test, this excludes time taken for sample collection) should be short.

Solubility test is good enough but it is not regularly done for its low sensitivity and specificity. Sickling test needs trained microscopist/ technician. TOT is also long, up to 24 hrs. Agarose gel electrophoresis is an art, needs good technician, costly, instrumentation, consumables, TOT is long, and cannot differentiate between $H B$ S,C,D disease in alkalinep ${ }^{H}$. Cellulose acetate electrophoresis is similar to agaroe gel but much more costlier than agarose gel. HPLC is a costly affair not suitable in indian scenario.

With some modifications, (Modified) Solubility Test corrects the fallacies of normal solubility test.

Keywords--- Mass Screening. Modifie Solubility Test, Solubility Test. Sickling Test, Electrophoresis, HPLC.
\end{abstract}

\section{INTRODUCTION}

Solubility test is based on the principle of relative insolubility of haemoglobin "S" when combined with sodium dithionite, a reducing agent. When whole blood is mixed with saponin, it is haemolysed and sodium diothinite reduces the haemoglobin, Deoxygenated HB-S is insoluble in the presence of a concentrated phosphate buffer. And so forms a turbid solution. Normal haemoglobin A and all other haemoglobins remain in solution under these conditions.

Haemoglobin electrophoresis, iso electric focussing, HPLC are used for the diagnosis of haemoglobinopathies in developed countries. PCR is also used for pre natal and neo natal diagnosis of haemoglobinopathies. But for developing countries the above tests are only done for confirmation of the diagnosis only. As the tests are very costly, they are not routinely done., The instruments, consumables ,trained technicians are normally not available in primary and secondary level hospitals

But there are many tests methods, with variable reliability, which are affordable. Most of these test don't require costly instrument. Per test cost is also low. These tests include sickling test, solubility test etc. By slight change in the method of solubility test, the reliability of the test can be changed a lot. And hence can be used for mass screening test.

\section{MATERIAL AND METHODS}

The study was conducted in RIMS ranchi. OPD paediatric patients with anaemia only were included. Sample size was 394 Since the study was conducted to establish the efficacy and 
reliability of solubility test, general population sampling was not done. From each of the patient 3 $\mathrm{ml}$ of blood was taken in EDTA tube and following tests were done

SICKLING TEST The principle of sickling test is based on microscopic observation of sickling of red blood cells when exposed to low oxygen tension. Equal volume of EDTA blood is mixed with $2 \%$ sodium meta bi sulphite. A drop of blood and reducing substance mixture is taken in glass slide and is covered with a cover slip, the four sides of cover slip is sealed with wax. The slide is seen under hp after 2, 4 and $24 \mathrm{hrs.}$

SOLUBILITY TEST- The principle is based on turbidity is created when haemolysed blood is mixed with sodium di thionite suspended in saturated phosphate buffer. Twenty micro litre of EDTA blood is mixed with $2 \mathrm{ml}$ of $0.02 \%$ sodium di thionite in a test tube. Left at RT for $5 \mathrm{mts}$. The samples were examined using light against the background of black lines. The results were interpreted as positive when black lines were not visible

MODIFIED SOLUBILITY TEST- EDTA blood is centrifuged for $20 \mathrm{mts}$ at 2000rpm,the supernatant plasma, buffy coat and little upper layer of packed cell is discarded. The rest of the packed cell is mixed with equal amount of normal saline. Mixed well, this rbc suspension is used as sample. With this sample a solubility test is performed
HAEMOGLOBIN ELECTROPHORESIS- With packed cell equal volume of distilled water is added and then centrifuged .This haemolysate is used as sample. Agarose gel 2\% is used as media. Buffer used is TEB, and $\mathrm{p}^{\mathrm{H}}$ 8.6. The principle of this method is based on the fact that proteins normally have either positive or negative charge that is determined by the charged amino acids they contain. When electric field is applied to a solution containing protein molecules positively charged proteins will move to the cathode and vice versa. Depending on their charges, size and shape different haemoglobin will separate and migrate at different rates. Bands are then stained and scanned for colour concentration compared with known controls.

HPLC- EDTA blood is passed through the cartridge with running buffer. The runtime is seen in the form of a graph. Position of bands are compared with known sample.

\section{RESULTS-}

Out of 394 patients, HB electrophoresis detected 372 HB AA,19 AS and 3SS.

Sensitivity of solubility test is $50 \%$ and specificity $10.54 \%$, where as sensitivity of MODIFIED solubility test is $66.66 \%$ and specificity $5.94 \%$.

Positive and negative predictive value for solubility test are respectively $23.52 \%$ \& $96.50 \%$ Positive and negative predictive value for modified solubility test are respectively $42.1 \%$ \& $97.75 \%$

\section{TABLE-}

\begin{tabular}{|l|c|c|c|c|}
\hline VARIABLE & SICKLING & SOLUBILITY & MODIFIED SOLUBILITY & HB. ELECTR \\
\hline TRUE POSITIVE & 20 & 12 & 16 & 22 \\
\hline FALSE POSITIVE & 2 & 39 & 22 & 0 \\
\hline FALSE NEGATIVE & 4 & 12 & 3 & 0 \\
\hline TRUE NEGATIVE & 368 & 331 & 398 & 394 \\
\hline TOTAL & 394 & 394 & $66.66 \%$ & $100 \%$ \\
\hline SENSITIVITY & $83.33 \%$ & $50 \%$ & $5.94 \%$ & $0 \%$ \\
\hline SPECIFICITY & $0.54 \%$ & $10.54 \%$ & $42.1 \%$ & $100 \%$ \\
\hline PREDICTIVE VALUE OF POSITIVE TEST & $90.90 \%$ & $23.52 \%$ & $97.75 \%$ & $100 \%$ \\
\hline PREDICTIVE VALUE OF NEGATIVE TEST & $98.92 \%$ & $96.50 \%$ & $33.33 \%$ & $0 \%$ \\
\hline PERCENTAGE OF FALSE NEGATIVE & $16.66 \%$ & $50 \%$ & $5.94 \%$ & $0 \%$ \\
\hline PERCENTAGE OF FALSE POSITIVE & $0.54 \%$ & $10.54 \%$ & & 0 \\
\hline
\end{tabular}




\section{JMSCR Vol||05||Issue||01||Pages 16055-16057||January}

\section{DISCUSSION}

Despite availability of a array of tests for sickle cell disease, still sickling test is a good screening test. While all the methods can detect homozygous SS state but can't detect heterozygous AS state. The probable reason for the high false positive rate in solubility test was that some of the samples might have shown erythrocytosis, marked leucocytosis, hyper lipidemia, hyper globulinemia etc.

By centrifuging the blood sample and by removing the plasma and buffy coat the sensitivity of MODIFIED solubility test increased very much but still sickling test is superior

\section{CONCLUSION}

Sickling test is the most reliable, cheapest and easiest to perform. It has high specificity and sensitivity. Solubility and modified solubility tests were more expensive and cumbersome. 